\title{
New recognition of NNE-strike belt of negative aeromagnetic anomaly in Tibetan plateau
}

\author{
HE Ri-Zheng ${ }^{1}{ }^{*}$ GAO Rui ${ }^{1}$ and ZHENG Hong-Wei ${ }^{2}$ \\ 1 Institute of Geology, Chinese Academy of Geological Sciences, Beijing 100037, CHINA \\ 2 Geophysical Department, Peking University, Beijing 100871, CHINA \\ * For correspondence, email: herizheng@cags.net.cn
}

The aeromagnetic data (see Figure 1) used in this study came from the survey of scale 1:1000000 in mid-west Tibetan plateau conducted by the Center of Aerial Survey and Remote Sensing of the Land and Resources Department in 1998-2000 (Xiong et al. 2001 ). This study adopts the matched-filter technique to obtain regional anomaly fields (He et al., 2007; Figure 2). It have a good agreement with upward continuation (Xiong et al. 2001), which shows that there is a regional NNE-trending negative anomaly belt in the middle part of Tibetan plateau. Figure 2 indicates that the source depth responsible for generating this negative anomaly belt is greater than the average depth of Curie isothermal surface in Tibetan plateau (Alsdorf and Nelson 1999). Below the Curie surface, rock magnetism is mainly caused by inductive magnetization, which is related to the regional tectonic stress field. The regional tectonic stress field is in turn dictated by regional deep structures and tectonics.

Shapiro et al. (2004) studied the seismic waveform data crossing the mid-western part of Tibetan plateau and considered that there was a near-NS low-velocity zone from $20 \mathrm{~km}$ down to the lower crust of Tibet, where the VSH is about $8 \%$ lower than the standard velocity. The result from Teleseismic P-wave tomography shows that the front of the subducting Indian lithospheric mantle reaches northward to the middle of Qiangtang terrane(He et al. 2006, Zheng 2006). Combining with the result of deep seismic profiling east-westerly crossing this low-velocity zone (Teng et al. 1994, Zhang et al. 2001), the synthesis indicates that the Indian lithospheric mantle beneath the plateau is deformed to a "spoon" shape, and the regional NNE-trending negative anomaly in the middle of the plateau is rightly in the center of the spoon. Beneath the northern part of Qiangtang terrane in middle Tibetan plateau, there is a mantle-originated low-velocity body (Zheng 2006, Zhou and Murphy 2005), whose position coincides with the region of low $\mathrm{Pn}$ velocity and insufficient $\mathrm{Sn}$ propagation (McNamara et al. 1997), on its top is the region of widespread potash volcanic rocks in northern Tibet (Deng et al. 1996 Hacker et al. 2000, Chung et al. 2005). This indicates that the front of Indian lithospheric mantle is not sutured together with that of Eurasian plate, resulting in a low-velocity anomaly body originated from the mantle (Zheng

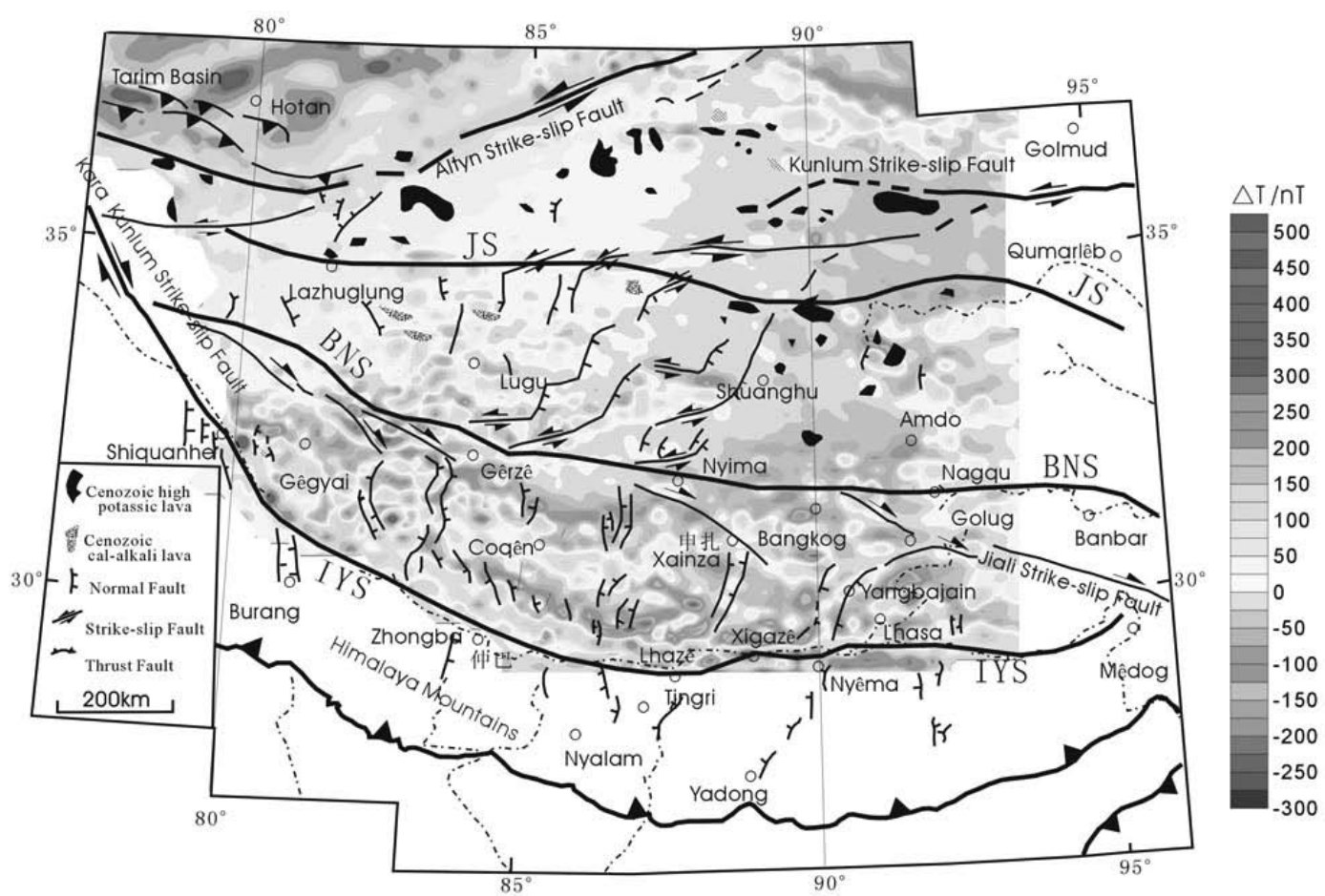

FIGURE 1. The map of aeromagnetic T anomaly reduced to the pole in mid-western Tibet Plateau. Tectonic base map from Yin et al. (2001). IYS: Indus-Yalung Zangbo Suture; BNS: Banggonghu-Nujiang Suture; JS: Jinshajiang Suture. 


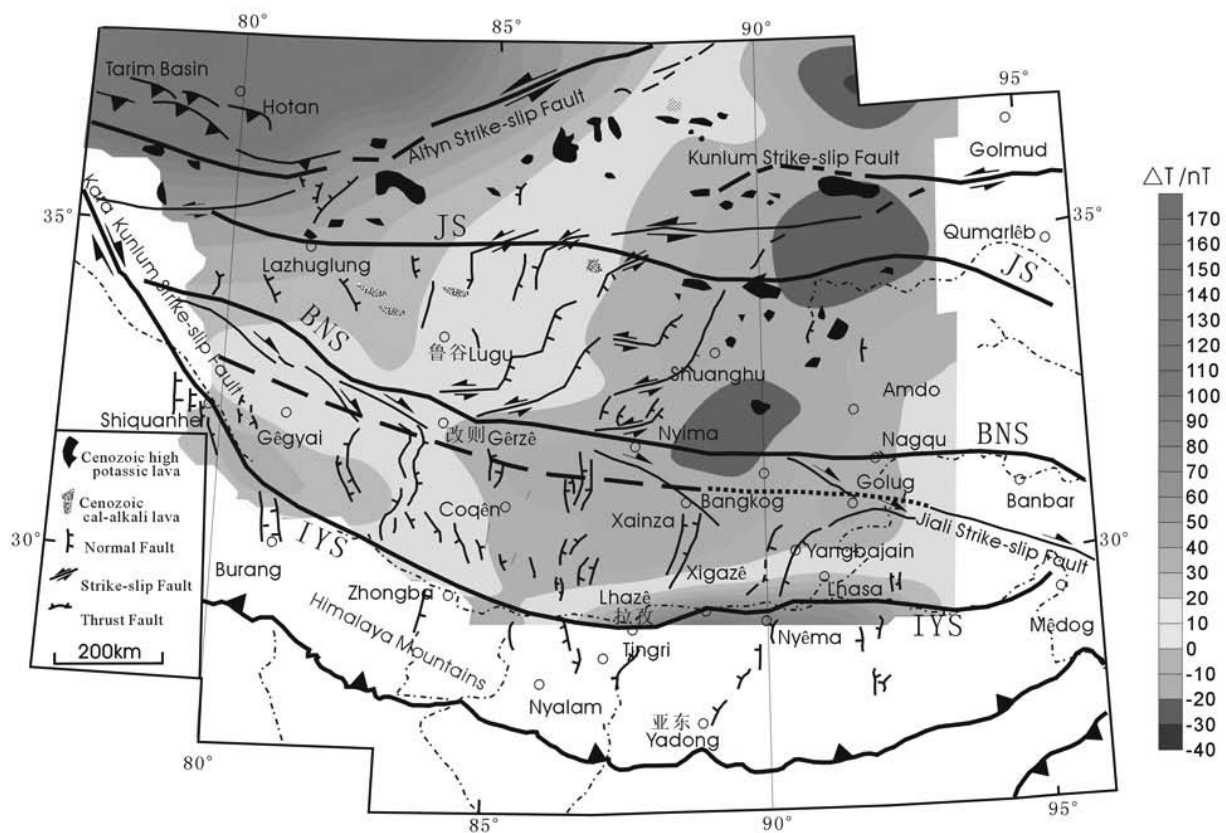

FIGURE 2. The regional magnetic anomaly field in mid-western Tibet Plateau (legends and tectonic basemap are the same as in Figure 1).

2006). The location of this low-velocity body is comparable to that of the NNE-trending negative aeromagnetic anomaly given in this paper. The anomalously hot material from deep mantle flows southward and upward along the NNE spoon-like Indian lithospheric mantle. This made the temperature of the primary lithosphere of midsouth Tibetan plateau on top of the spoon-like Indian lithospheric mantle to rise anomalously, resulting in an enclosed NNE-trending thermal anomaly zone, which caused thermal demagnetization of the magnetic minerals inside the lithosphere of middle Tibetan plateau. In this way the regional NNE-trending negative aeromagnetic anomaly belt was formed.

\section{Acknowledgement}

This work was supported by grants from Nation Science foundations Tian Shan project of US and National Natural Science Foundations of China (No.40404011, 40774051), 2007Year of the Basic outlay of scientific research work from Ministry of Science and Technology of the People's Republic of China, International Cooperative Project from Ministry of Science and Technology of the People's Republic of China No.2006DFA21340, Open Fund (No. GDL0602) of Geo-detection Laboratory, Ministry of Education of China, China University of Geosciences.

References

Alsdorf D and D Nelson. 1999. Tibetan statellite magnetic low: evidence for widespread melt in the Tibetan crust? Geology 27(10): 943-946

Chung Sun-Lin, Chu Mei-Fei, and Zhang Yuquan. 2005. Tibetan tectonic evolution inferred from spatial and temporal variations in postcollisional magmatism. Earth Science Reviews 68: 173-196

Deng W, X Zheng and Y. Matsumoto. 1996. Petrological characteristics and ages of Cenozoic volcanic rocks from the Hoh Xil Mountains, Qinghai. Acta Petrologica et Mineralogica (in Chinese with English abstract) 15 (4): 289-298

Hacker BR, E Gnos and L Ratschbacher. 2000. Hot and dry deep crustal xenoliths from Tibet. Science 287: 2463-2466
He R, ZDP Zhao and R Gao. 2006.Teleseismic P-wave tomography under the central Tibet Plateau, Eos Trans. AGU 87(36) West. Pacific Geophysics Meet, Supplementary, Abstract: T12B-04

He RZ, R Gao, HW Zheng and JS Zhang. 2007. Matched-filter analysis of aeromagnetic anomaly in mid-western Tibetan plateau and its tectonic implications. Chinese Journal of. Geophysics (in Chinese) 50(4): 1131-1140

McNamara DE, WR Walter and TJ Owens. 1997. Upper mantle velocity structure beneath the Tibetan plateau from Pn travel time tomography. Journal of Geophysical Research 102: 493-505

Shapiro NM, MH Ritzwoller and P Molnar. 2004. Thinning and flow of Tibetan crust constrained by seismic anisotropy. Science 305: 233-236

Teng JW, ZX Yin and HB Liu. 1994. 3-D and 2-D structure of Tibetan lithosphere and continental dynamics. Chinese Journal of. Geophysics (Acta Geophysica Sinica) (in Chinese) 37 (Suppl. II): 117-130

Xiong SQ, FH Zhou, ZX Yao, DJ Xue and SL Duan (Editors). 2001. Areomagnetic survey in Central and western Qinghai-Tibet plateau (in Chinese with English abstract) Beijing: Geological Publish House.

Yin A. 2001. Geologic evolution of the Himalayan-Tibtan orogenPhanerozoic growth of Aisa continetal. Acta Geoscientia Sinica (in Chinese) 22(3): 193-230

Zhang ZJ, Li YK, Wang GJ. 2001. E-W crustal structure of North Tibet and "Sunken" Moho - an implication from wide-angle reflection profile. Science in China (Series D) 31(11): 881-888

Zheng HW. 2006. 3-D velocity structure of the crust and upper mantle in Tibet and its geodynamic effect. (Ph. D. dissertation) Beijing, Chinese Academy Geological Sciences.

Zhou FH, ZX Yao and ZJ Liu. 2002. The origin and implication of the NNE-trending deep negative magnetic anomaly zone in Central Qinghai-Tibet plateau. Geophysical and Geochemical Exploration (in Chinese with English abstract) 26(1): 12-16.

Zhou HW and MA Murphy. 2005. Tomographic evidence for wholesale underthrusting of India beneath the entire Tibetan plateau. Journal of Asian Earth Science 25: 445-457 